\title{
Liver regeneration is associated with lipid reorganization in membranes of the endoplasmic reticulum
}

\author{
Anatoly I. Bozhkov $(\bowtie)^{1}$, Natalia G. Menzyanova ${ }^{2}$, Vadim V. Davydov ${ }^{3}$, Natalia I. Kurguzova ${ }^{1}$, Vadim I. Sidorov ${ }^{1}$, \\ Anastasia S. Vasilieva ${ }^{1}$ \\ ${ }^{1}$ Research Institute of Biology of V.N. Karazin Kharkov National University, sq. Svobody, 4, 61022 Kharkov, Ukraine \\ ${ }^{2}$ Institute of Fundamental Biology and Biotechnology of Siberian Federal University, pr. Svobodny, 79, 660041 Krasnoyarsk, Russia \\ ${ }^{3}$ Ryazan State Medical University named after academician I.P. Pavlov, Visokovoltnaya 9, 390026 Ryazan, Russia
}

(C) Higher Education Press and Springer-Verlag Berlin Heidelberg 2016

BACKGROUND: In recent years, an adaptive endoplasmic reticulum (ER) stress response has been actively investigated. The ER membrane, isolated from the intact and regenerating liver, may be an appropriate model for investigating the association between structural and functional characteristics of ER in vivo and their corresponding behavioral characteristics in vitro. The rate of lipid synthesis and that of intracellular lipid exchange between the ER and cytosol were investigated in the intact and regenerating liver (13 h after partial hepatectomy). Particularly, membrane characteristics, surface potential, and glucose 6phosphatase (G6Pase) activity were investigated, along with the degradation rate of G6Pase in vitro, which was estimated by the loss of G6Pase activity, formation of lipid peroxides, and size of excreted membrane vesicles.

METHODS: The rate of lipid synthesis was determined by measuring the intensity of radioactive precursor $\left(\mathrm{C}^{14}\right.$-sodium acetate) in different fractions of lipids (phospholipids, non-esterified fatty acids, and triacylglycerides) after 30 min exposure. The rate of lipid metabolism was assessed by measuring the quantity of lipids with radioactive labels emerging in the cytosol of hepatocytes (CPM). Viscosity and surface potential were determined by fluorescent probes.

RESULTS: It was observed that after $13 \mathrm{~h}$ of partial hepatectomy, the rate of lipid synthesis in the ER of hepatocytes in the regenerating liver was 3 times lower than that in ER of hepatocytes in the intact liver, wherein the rate of incorporation of newly synthesized lipids in cytosol was several times higher in the regenerating liver. Increase in the rate of exchange of neutral lipids in cells of the regenerating liver was accompanied by lipid reconstruction in the ER, changing the structural and functional characteristics of the membrane. Such membrane rebuilding also contributed to the rate of degradation of the ER in vitro, which that must be taken into account during development of systems for in vitro assessment of xenobiotic metabolism.

CONCLUSIONS: An increase in the rate of direct (microsomes $\rightarrow$ cytosol) and reverse transport of lipids (cytosol $\rightarrow$ microsomes) was observed in the regenerating liver. Microsomes, isolated from the regenerating liver, were degraded in the in vitro system at a higher rate.

Keywords regeneration, neutral lipids, microsomes in vitro

\section{Introduction}

The endoplasmic reticulum (ER) plays a role in most metabolic processes in the cell, such as regulation of protein synthesis on membrane-bound ribosomes (Vitale et al., 1993; Braakman and Hebert, 2013), synthesis of lipids (Fagone and Jackowski, 2009; Fu et al., 2012), metabolism of saccharides (Hebert et al., 2005), energy exchange (Wagner and Moore,

Received June 15, 2016; accepted August 15, 2016

Correspondence: Anatoly I. Bozhkov

E-mail: bozhkov@univer.kharkov.ua
2011), and detoxification of xenobiotics (Schwarz and Blower, 2008). Owing to crossover of different metabolic pathways in the ER, it cooperatively controls all the metabolic activities of the cell.

The methods employed for evaluation of the effects of xenobiotics on animal models are often not in accordance with contemporary bioethics standards. Therefore, those systems involving cytochromes, localized in ER, are of particular importance. Such methods would be effective only if a synergistic approach considering the functions of ER in detoxification of xenobiotics and initial condition of ER is adopted. This would allow selection of appropriate models for studies on ER systems, as their initial structural and 
functional condition would affect the features and intensity of detoxification.

Thus, a change in lipid composition of membranes is accompanied by their cooperative rebuilding and changes in the activity of membrane-bound enzymes, which subsequently leads to changes in energy, protein, and carbohydrate metabolism along with changes in detoxification. Investigation of cooperative mechanisms for the regulation of metabolism is one of the most important research areas in modern biology (Bozhkov and Menzianova, 2009).

In recent years, an adaptive ER stress response called the unfolded protein response (UPR) has been actively investigated (Walter and Ron, 2011). Distortion in protein folding leading to accumulation of aberrant proteins in ER and their further aggregation is called ER-stress (Schönthal, 2012; Cao and Kaufman, 2014). Additionally, ER-stress is accompanied by the development of type 2 diabetes mellitus, neurodegenerative diseases, and other metabolic disorders (Back and Kaufman, 2012). We believe that ER-stress may also affect detoxification. Additionally, excessive quantity of neutral lipids in the ER leads to the change in structural and functional characteristics of the ER; however, the role of neutral lipids in ER-stress is not clearly established.

ER membranes, isolated from the intact and regenerating liver, may be an appropriate model for investigation of the association between structural and functional characteristics of ER in vivo and their corresponding behavioral characteristics in vitro. Additionally, such investigations are important for understanding the role of intracellular membranes in the process of liver regeneration. We believe such studies revealing synthesis, transportation, and content of lipid elements in membranes to be of profound interest. The role of phospholipids is well known, but the role of neutral lipids, such as triacylglycerides and non-esterified fatty acids, has not been fully investigated.

It is known that after $12-13 \mathrm{~h}$ of surgical removal of $2 / 3^{\text {rd }}$ of the liver, the hepatocytes are in the G-1 phase of the cell cycle, and after 22-24 h, they relatively synchronously step into the S-phase of the cell cycle (Keyomarsi et al., 1991). Such experimental synchronization of hepatocytes during progression of cell cycle allows the investigation of the structural and functional adaptive rebuilding of the ER in actively dividing cells.

In the current study, based on the above understanding, we determined the content of lipid elements (total lipids, phospholipids, nonesterified fatty acids, triacylglycerides) in ER extracted from the intact and regenerating liver $(13 \mathrm{~h}$ after partial hepatectomy), the rate of their synthesis, and the rate of transportation of newly synthesized (marked by ${ }^{14} \mathrm{C}$-sodium acetate within $30 \mathrm{~min}$ ) lipids to cytosol. For determination of structural and functional characteristics, fluorescent probes (pyrene and 1,8-anilinonaphthalene-sulfonic acid) were used and the activity of membrane-bound enzyme, glucose 6phosphatase (G6Pase), was evaluated. To assess the behavioral characteristics of ER in vitro, the rate of formation of lipid hydroperoxides, activity of G6Pase, and sizes of membrane vesicles in sucrose gradient were determined.

\section{Materials and methods}

The experiments were conducted on 3-month-old Wistar rats. Partial hepatectomy was performed by a previously described method (Higgins and Anderson, 1931) $13 \mathrm{~h}$ before sacrificing the rats. Lipid content was determined in the liver cytosol after $0.5,1,2,3,6,12,16,20,24,48,96,144$, and $192 \mathrm{~h}$ after partial hepatectomy. These time points, were chosen because a major part of the regeneration process is observed during this period. The duration between time points at the initial stage of regeneration was shorter, because the changes at this stage are faster. When determining the rate of lipid synthesis, the animals were injected with $\left[{ }^{14} \mathrm{C}\right]$-sodium acetate $(5.5$ $\mathrm{MBq} / 100 \mathrm{~g}$ body mass) $30 \mathrm{~min}$ prior to sacrifice. Control and experimental groups consisted of 20 animals each. All experiments with animals were conducted in compliance with the rules of ethics (Council Directive 86/609/EEC, 1986).

To obtain an overview of changes in the liver during regeneration, transmission electron microscopy (TEM) of the samples from the regenerating liver was performed. Samples were fixed in $2 \%$ formaldehyde prepared in $0.1 \mathrm{M}$ phosphate buffer, $\mathrm{pH}=7.4$, for $24 \mathrm{~h}$. The tissue samples were incubated in $1 \%$ osmium tetroxide for $2 \mathrm{~h}$ post fixation. To obtain a contrasting image of the samples, they were incubated in $1 \%$ uranyl acetate for $12 \mathrm{~h}$ at $4^{\circ} \mathrm{C}$. Tissue samples were embedded in Epon for TEM; the ultrathin preparations were contrasted in $2 \%$ uranyl acetate and 3\% lead citrate solutions.

Microsomal and cytosolic fractions were isolated from the liver of control (intact) and experimental (partial hepatectomy) rats following perfusion with cold $0.25 \mathrm{M}$ sucrose as previously described (Kamath and Narayan, 1972). Lipids were extracted from the isolated microsomes and cytosol (Bozhkov and Dlubovskaya, 1995). They were fractionated by thin layer chromatography using silufol plates (hexane: acetic acid diethyl ester:methanol:glacial acetic acid $(9: 2: 0.2: 0.3 \mathrm{v} / \mathrm{v})$ was used as solvent system) followed by qualitative and quantitative determination of their specific radioactivities as previously described (Jork et al., 1994). The radioactivity of labeled compounds was determined in the acid-soluble fraction of an aliquot of homogenate obtained after precipitation with $5 \%$ perchloric acid. The radioactivity was measured using dioxane scintillator $(5 \mathrm{~g}$ PPO, $0.25 \mathrm{~g}$ POPOP, $100 \mathrm{~g}$ naphthalene) with a Beckman LS-7800 counter (USA). The rate of transportation of ${ }^{14} \mathrm{C}$-labeled lipids from the microsome to the cytosol was assessed by the content of labeled lipids in cytosol after $30 \mathrm{~min}$ of exposure with a radioactive precursor.

The size of microsomal vesicles was assessed in a $10 \%-$ $50 \%$ sucrose gradient, which was prepared in $10 \mathrm{mM}$ tris- $\mathrm{HCl}$ buffer (pH 7.4) with $5 \mathrm{mM} \mathrm{MgCl}_{2}$. The test mixture contained 
one portion of suspension of microsomes, which was added in cuvette with 1-cm pathlength, with quantity of microsomes corresponding to 10 units of absorption at $260 \mathrm{~nm}$. Microsome suspension specimens were centrifuged at $90000 \times g$ for $2 \mathrm{~h}$ and $15 \mathrm{~min}$ at $4^{\circ} \mathrm{C}$. The distribution of vesicles in the density gradient was determined by measuring the absorbance of material at less than $260 \mathrm{~nm}$ on spectrophotometer SF-46 ("Lomo," Russia) in a flow-cell.

Membrane-bound G6Pase activity was determined in microsomes as previously described (Alegre et al., 1988), the protein content was evaluated by Lowry's method (Lowry et al., 1951), and lipid hydroperoxide content was determined by a previously described method (Ohkawa et al., 1979). The fluorescence spectrum of pyrene and 1-anilinonaphthalene-8sulfonic acid (1,8ANS) was determined by a spectrofluorimeter ("MPF-2A Hitachi", Japan), as previously described (Krishnan and Balaram, 1975). The obtained results were statistically analyzed according to the Student criterion (Zimmerman, 1997).

\section{Results}

\section{Synthesis of lipids and lipid exchange in ER}

Intensity of the radioactive precursor in labeled total lipids in microsomes of the regenerating liver was 3.5 times lower than that in microsomes of the intact liver (Fig. 1A). Such a decrease in relative radioactivity in microsomes of the regenerating liver was relevant also for the fractions of phospholipids, non-esterified fatty acids (NFA), and especially, triacylglycerides (Fig. 1A). These results suggested that the lipid content in microsomes of the regenerating liver may be different from that in microsomes of the intact liver. The lipid content in microsomes of the regenerating liver increased by $18 \%$ compared to that in microsomes of the intact liver. Contents of NFA and triacylglycerides in microsomes of the regenerating liver increased by $39 \%$ and $38 \%$, respectively, as compared to the contents in microsomes of the intact liver; however, the content of phospholipids in microsomes of regenerating liver was unchanged as compared to that in microsomes of the intact liver (Table 1).

Such a mismatch between the two functionally related parameters (decrease in synthesis of lipids, but increase in lipid content in microsomes) may be explained by a high speed of transportation of newly synthesized lipids from membranes to cytosol or it can be assumed that the lipids synthesized earlier (unlabeled) are embedded into the membranes. The rate of exchange of newly synthesized lipids with cytosol in the cells of the regenerating liver were found to be certainly higher than that in the cells of the intact liver (Fig. 1B).

Increase in speed of transport of lipids in the cytosolic fraction was in accordance with the results of the content of lipids in the cytosol $13 \mathrm{~h}$ after partial hepatectomy (Table 2). The content of total lipids, phospholipids, non-esterified fatty acids, and triacylglycerides was increased by $2.3,2.3,2.2$, and 3.9 times, respectively (Table 2).

Therefore, newly synthesized lipids are transported from the ER to the cytosol in the regenerating liver at a higher rate

Table 1 The content of lipids in the microsomal fraction ( $\mu \mathrm{g}$ lipids per mg of protein) of intact and regenerating rat liver $(13 \mathrm{~h}$ after surgery, $n=15)$

\begin{tabular}{lllll}
\hline Variant of experiment & \multicolumn{3}{c}{ Lipid fraction } \\
\cline { 2 - 5 } & Total lipids & Phospholipid & NFA & TG \\
\hline Intact liver & $325.4 \pm 4.5$ & $184.5 \pm 7.1$ & $17.2 \pm 1.1$ & $32.1 \pm 1.6$ \\
Regenerating liver & $383.6 \pm 4.1^{*}$ & $207.9 \pm 14.0$ & $24.0 \pm 1.5^{*}$ & $44.2 \pm 2.8^{*}$ \\
\hline
\end{tabular}
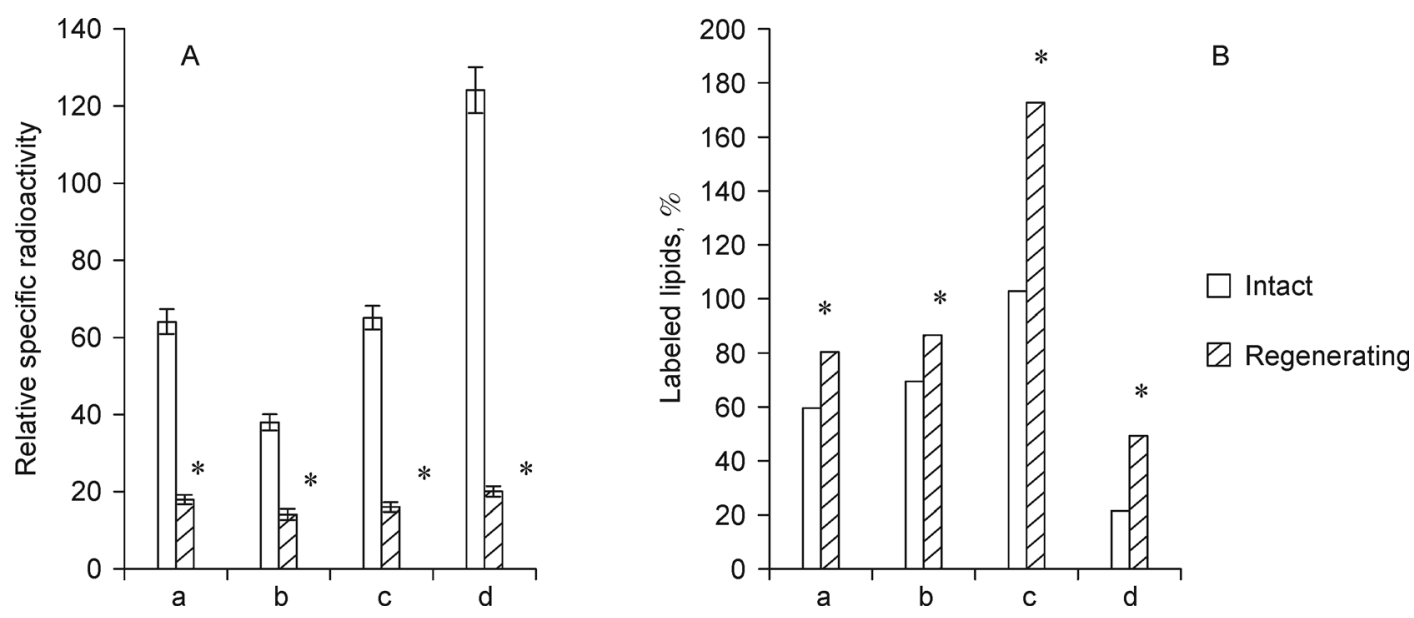

Figure 1 Relative specific radioactivity (specific radioactivity $\mathrm{cpm} / \mathrm{min} \times \mathrm{mg}$ microsomal lipid/lipid pool specific radioactivity precursors $\times 100$ ) of $(\mathrm{A})$ lipids of ER membrane; and (B) lipids of cytosol. The abscissa: a-total lipids; b-phospholipids; c-non-esterified fatty acids; d-triacylglycerols, ${ }^{*} p \leqslant 0.05$ presents the average values of 20 experiments. 
Table 2 The content of lipids in the cytosol fraction ( $\mu \mathrm{g}$ lipids per mg of protein) of intact and regenerating rat liver ( $13 \mathrm{~h}$ after surgery) $\mathrm{n}-$ number of repetitiveness in staples

\begin{tabular}{|c|c|c|c|c|}
\hline \multirow[t]{2}{*}{ Variant of experiment } & \multicolumn{4}{|c|}{ Lipid fraction } \\
\hline & Total lipids & Phospholipid & NFA & TG \\
\hline Intact liver & $\begin{array}{c}92.6 \pm 5.8 \\
(39)\end{array}$ & $\begin{array}{l}13.9 \pm 1.3 \\
\quad(28)\end{array}$ & $\begin{array}{c}14.2 \pm 1.3 \\
(30)\end{array}$ & $\begin{array}{c}40.1 \pm 3.0 \\
(36)\end{array}$ \\
\hline Regenerating liver & $\begin{array}{c}213.5 \pm 22.5^{*} \\
\quad(31)\end{array}$ & $\begin{array}{c}33.5 \pm 2.3 * \\
(30)\end{array}$ & $\begin{array}{c}31.5 \pm 2.6^{*} \\
(34)\end{array}$ & $\begin{array}{c}159.5 \pm 19.4^{*} \\
(27)\end{array}$ \\
\hline
\end{tabular}

compared to previously synthesized lipids, i.e., unlabeled lipids. It should be noted that the rate of transport of labeled phospholipids in the regenerating liver only slightly exceeded that in the intact liver, while the rate of transport of NFA and triacylglycerides exceeded the control level by $2-3$ times (Fig. 1B).

Therefore, an increase in the content of neutral lipids, including unlabeled lipids, in the ER of the regenerating liver is associated with the activation of reverse transport, i.e., from the cytosol to the ER. This process results in a decrease in specific radioactivity of lipids owing to the dilution of labeled lipids with unlabeled lipids and increase in specific radioactivity of lipids in the cytosol. We hypothesize that an increase in the rate of direct (microsomes $\rightarrow$ cytosol) and reverse transport of lipids (cytosol $\rightarrow$ microsomes) can be observed in the regenerating liver. Neutral lipid content in the cytosol of cells in the regenerating liver increased nonlinearly; it reached a maximum at $13 \mathrm{~h}$ after partial hepatectomy and decreased to the control level at $96 \mathrm{~h}$ after partial hepatectomy (Fig. 2A). TEM images reveal a high amount of lipid aggregates, also called lipid drops, in hepatocytes (Thiam et al., 2013), which occupied a large volume of cells (Thiam et al., 2013) (Fig. 2C). In cells of the regenerating liver, the newly synthesized lipids are rapidly transported from the place of synthesis (ER system) to the cytosol, where they form different storage sites - lipoproteins and lipid drops.

Lowering of excimerization of the fluorescent probe, pyrene, and simultaneous increase in the intensity of the fluorescence of $1,8 \mathrm{ANS}$ is observed in microsomes at $13 \mathrm{~h}$ after partial hepatectomy (Fig. 3). These phenomena indicate two processes: excimerization of pyrene indicates a decrease in membrane fluidity, and increase of 1,8ANS fluorescence indicates an increase in probe binding to low polarity regions of a protein surface.

Simultaneously, with an increase in the surface potential of
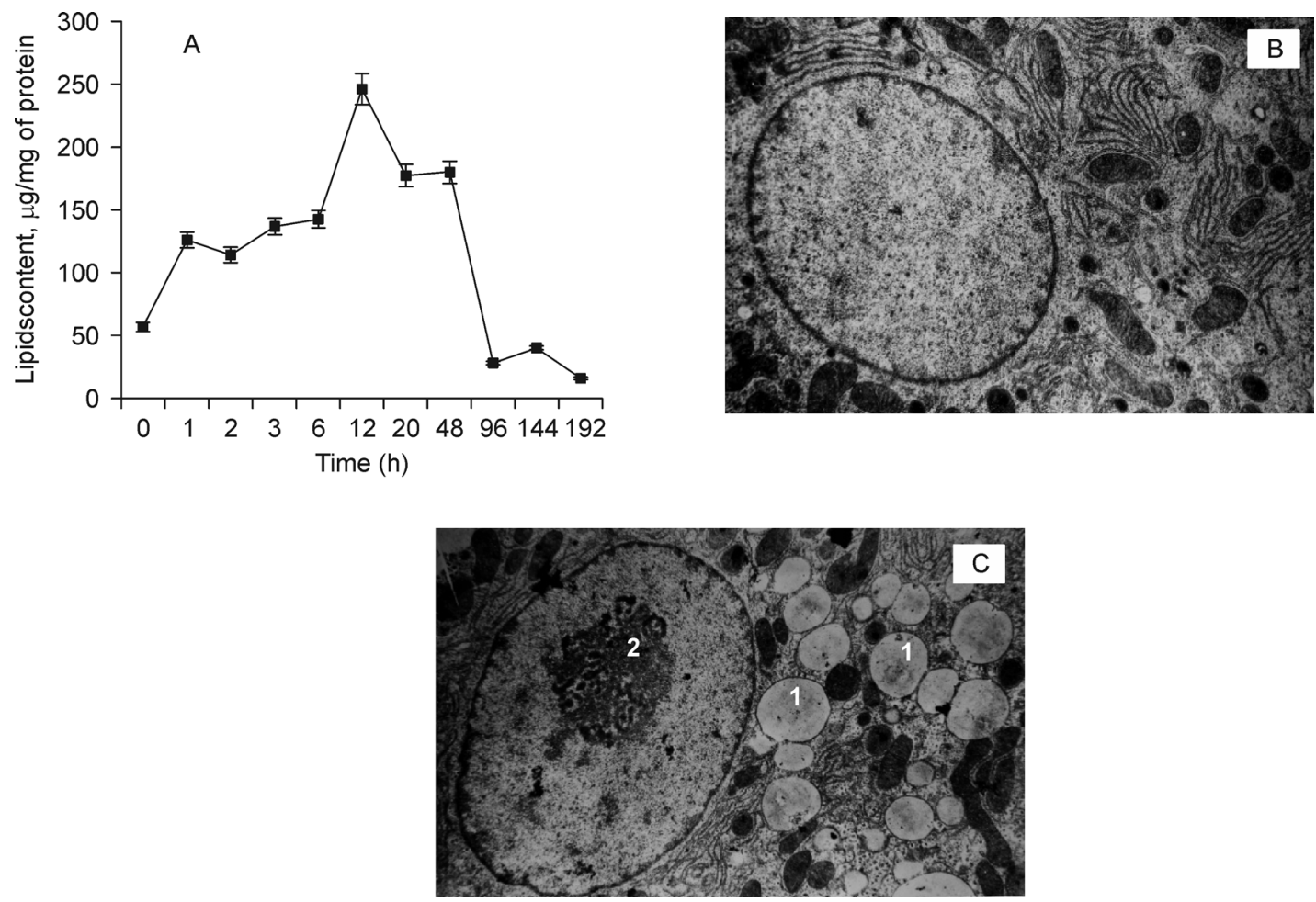

Figure 2 (A) Dynamics of total lipid content in cytosolic fraction of hepatocytes 0.5-196 h after partial hepatectomy; (B) Morphology of the intact liver; and (C) Morphology of the regenerating liver. Numerous lipid droplets in, 1 - cytoplasm; 2 - nucleolus. Magnification $25000 \times$. 
microsomes from the regenerating liver and microviscosity of membranes, the activity of G6Pase is decreased (Fig. 3C).

Therefore, partial hepatectomy induced structural and functional rebuilding of the ER in the remaining hepatocytes. Changes in microviscosity, surface potential, and membranebound enzyme activity were noted. In such rebuilding, the transport of neutral lipids (NFA and triacyglycerides) between ER membranes and the cytosol plays a major role. The results obtained suggest that direct (microsomes $\rightarrow$ cytosol) and reverse (cytosol $\rightarrow$ microsomes) lipid transport is drastically increased in the regenerating liver.

\section{Structural and functional characteristics of microsomes from the regenerating liver at $13 \mathrm{~h}$ after partial hepatectomy}

G6Pase is associated with the microsomal membrane, and its activity is considered an indicator of the physico-chemical properties of microsomal membranes. The activity of G6Pase in microsomes isolated from the regenerating liver was significantly lower than that in microsomes isolated from the intact liver. The activity of membrane-bound G6Pase during the incubation of microsomes isolated from the intact and regenerating liver decreased linearly up to $48 \mathrm{~h}$ and further stayed stable at a low level in a buffered solution at $20^{\circ} \mathrm{C}$ (Fig. 4A). G6Pase activity of microsomes isolated from the intact liver was $57 \%$ of the initial level for $24 \mathrm{~h}$ of incubation, but that of microsomes isolated from the regenerating liver was only $19 \%$. Activity of G6Pase in microsomes isolated from the intact and regenerating liver was the same when measured after $48 \mathrm{~h}$, and the activity did not differ between the samples (Fig. 4A).

The level of oxidized lipids (by formation of MDA) in microsomes isolated from the intact liver of animals after their incubation for $48 \mathrm{~h}$ at $20^{\circ} \mathrm{C}$ increased 3.3 times compared to the initial level. For microsomes isolated from the regenerat-
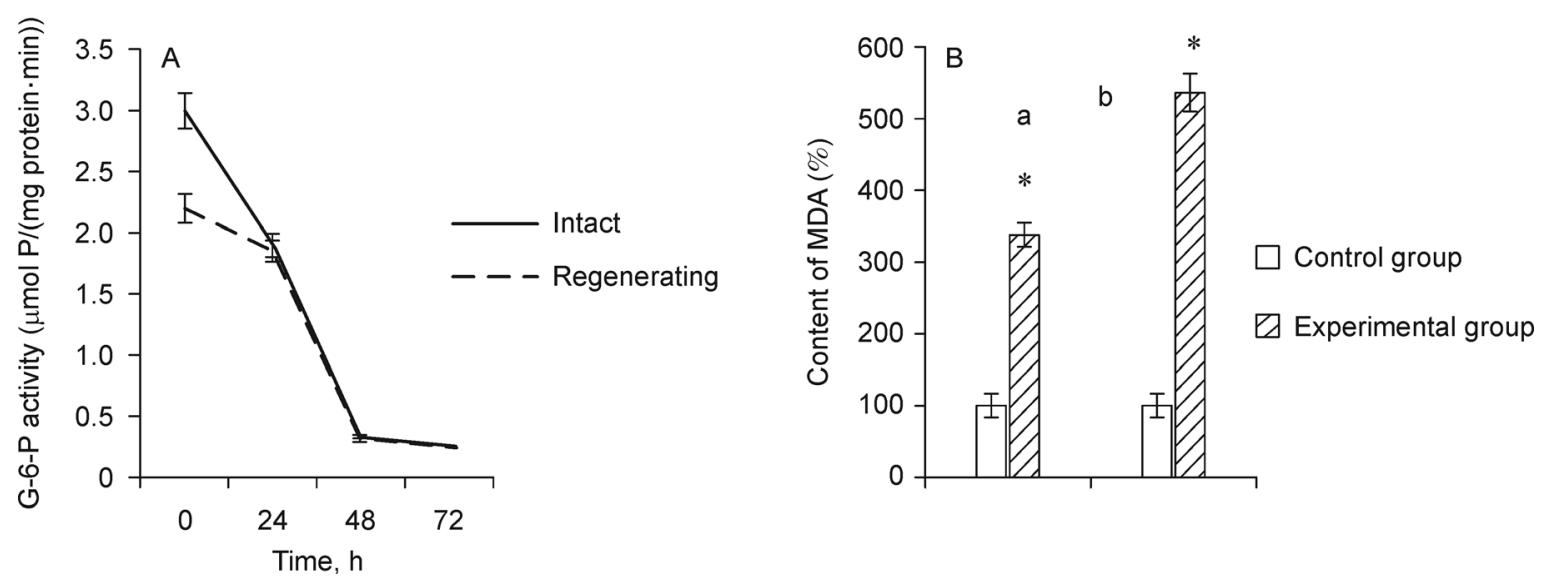

Figure 3 (A) Degree of excimerization of pyrene; (B) maximum intensity of the fluorescent 1,8-ANS probe; and (C) hydrolysis of glucose-6-phosphatase in microsomes of the intact and regenerating rat liver (13 $\mathrm{h}$ after partial hepatectomy).
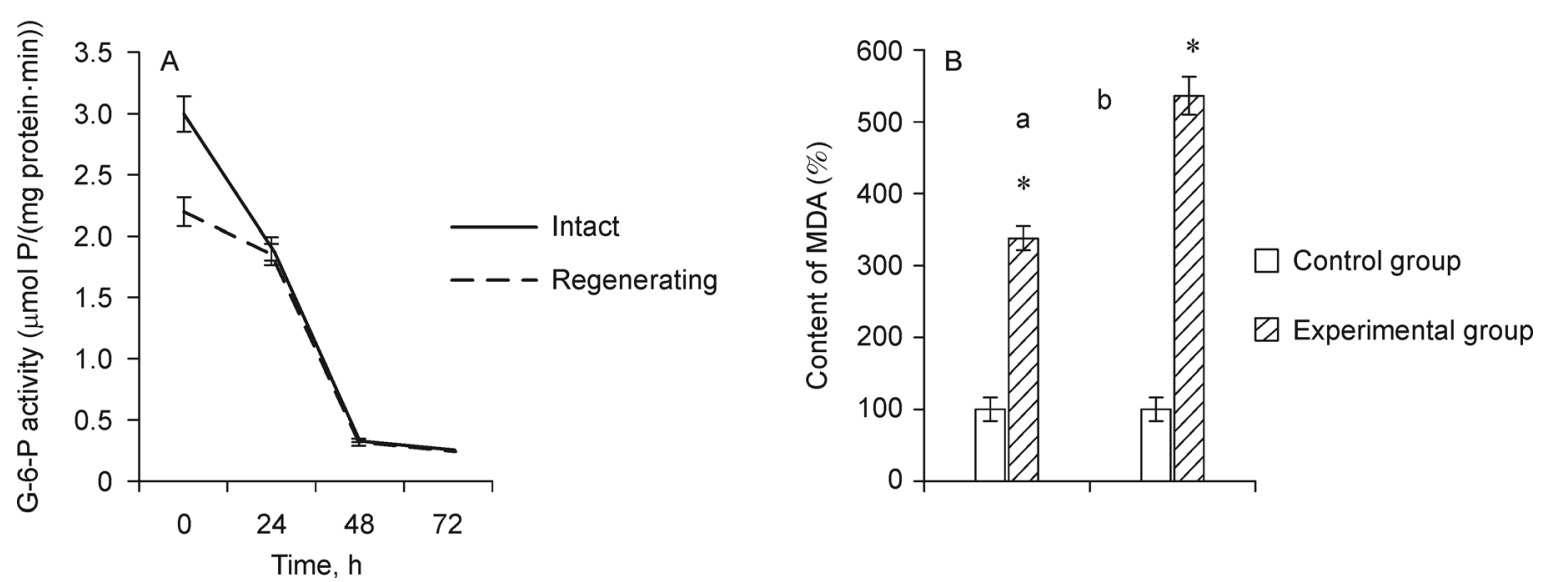

Figure 4 (A) Changes in the activity of G-6-phosphatase in microsomes isolated from the intact and regenerating liver during their incubation in in vitro system from 0 to $72 \mathrm{~h}$ at $20^{\circ} \mathrm{C}$ (A), and (B) the content of MDA microsomes (B) after incubation for $24 \mathrm{~h}$ at $20^{\circ} \mathrm{C}$ and their content without incubation, which was considered as $100 \%$.

$\mathrm{a}-$ Microsomes isolated from the intact liver; $\mathrm{b}-$ Microsomes isolated from the regenerating liver. 
ing liver, the content of lipid hydroperoxides under similar conditions increased by 5.3 times (Fig. 4).

Therefore, an elevated content of neutral lipids in microsomes from the regenerating liver is accompanied by a higher amount of lipid hydroperoxides produced per unit time; however, there is no direct correlation between the amount of lipid hydroperoxides in the ER and the activity of G6Pase. Microsomes from the regenerating liver in vivo were found to have differences in surface potential; therefore, after incubation of microsomes in vitro, they were separated according to size in a density gradient of $10 \%-50 \%$ sucrose, prepared in an incubation buffer (Fig. 5A).

Collectively, it was observed that after $48 \mathrm{~h}$ of incubation, ER vesicles from the intact liver were separated into two fractions according to size (Fig. 5B), and microsomes isolated from the regenerating liver under similar conditions demonstrated an increase in the heterogeneity of vesicles according to size, confirming a high degradation rate in vitro (Fig. 5B).

Therefore, the behavior and functional response of microsomes in vitro depends on the initial structural and functional characteristics of the ER. Microsomes isolated from the regenerating liver were degraded at a higher rate in vitro.

\section{Discussion}

The first signals for the initiation of regeneration are created in the liver itself. This is associated with a drastic increase in the functional load on remaining cells and, consequently, with hyperplasia of different types of hepatocytes. These first signals are produced by Kupffer cells and lymphocytes (Fausto and Riehle, 2005). Until now, more than 10 factors that affect proliferation of hepatocytes, such as hepatopoetins, epidermal growth factor, transforming growth factor, platelet

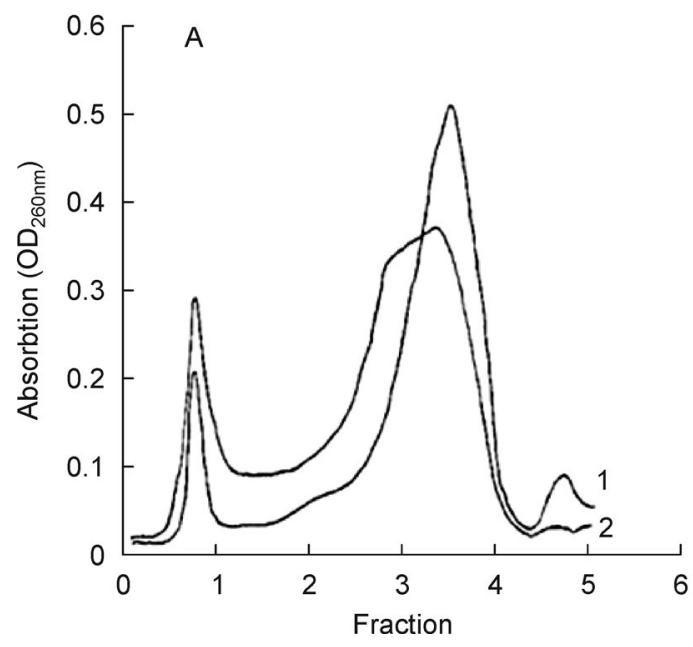

factor, and insulinoid factor, have been identified (Wynn, 2008). It is known that Kupffer cells produce cytokines and accumulate lipids (Dai et al., 2009).

The role of cytokines in the regulation of proliferation has received considerable attention; we can now say that cytokines are links in a series of complex processes that control regeneration. Crucial components in this series are neutral lipids. During initial stages after the partial hepatectomy, the transport of neutral lipids from the circulating blood into the liver and from the cytosol to the ER is increased. Simultaneously, specific lipid loading proteins transfer newly synthesized lipids from sites of their synthesis, which are the ER membranes, into the cytosol. Such increase in the direct (microsomes $\rightarrow$ cytosol) and reverse transport (cytosol $\rightarrow$ microsomes) of neutral lipids along with cytokines causes a new lipid distribution pattern in cells of the regenerating liver and creates conditions for reparative regeneration. Such functional steatosis is a relatively short-term event, which ends simultaneously with liver regeneration.

Functional steatosis reorganizes the ER and changes the redox potential of the whole cell. In this study, we have shown that cells of the intact liver can be separated in a sucrose gradient into at least two fractions according to the lipid content - light or heavy (Sukach et al., 1997). This shows that an intact liver has at least two cell populations classified according to content of neutral lipids in the cytosol. Previous studies have shown that there were no cells in the heavy fraction and all types of cells were separated as the light fraction, i.e., they all were rich in lipids at $13 \mathrm{~h}$ after partial hepatectomy (Sukach et al., 1997). The lipid content increases in the ER and the cytosol in the form of lipoproteins and appear as large lipid aggregates called lipid drops (Fig. 2).

Such specific deposition of neutral lipids in the cytosol of cells of the regenerating liver may be regarded as a mechanism of metabolic reprogramming of cells. There is a

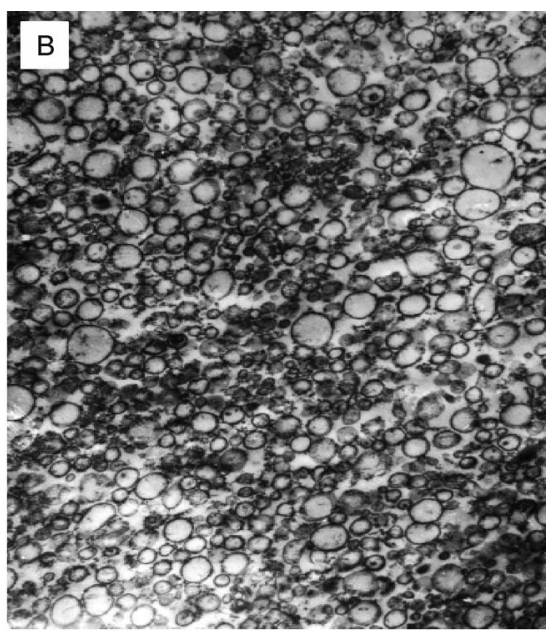

Figure 5 Separation of microsomal fractions by sucrose density gradient (10\%-50\%), prepared in $10 \mathrm{mM} \mathrm{Tris-HCl}+5 \mathrm{mM} \mathrm{MgCl} 2$. (1) Microsomes isolated from the intact liver; and (2) Microsomes isolated from the regenerating liver.

(A) The separation was performed by centrifuging at $95000 \mathrm{~g}$ for $2 \mathrm{~h} 15 \mathrm{~min}$ at $4^{\circ} \mathrm{C}$; (B) TEM images of membrane vesicles of liver cells. Magnification $25000 \times$ 
possibility that in such conditions, these cells are able to perform different functions, such as metabolic and proliferative activities. With the termination of the regeneration of liver mass and utilization of lipid storage sites, the simultaneous implementation of proliferative and specific metabolic functions of the liver is completed and the ability to proliferate is lost.

It is well known that functions of neutral lipids in cells are varied, but as previously discussed, they are involved only in energy- and biogenetics (membrane assembly)-related activities (Schneiter and Toulmay, 2007). Changes in lipid content of ER were accompanied by changes in the microviscosity of membranes, an increase in the membrane surface potential, and as a result, a decrease in the activity of membrane-bound G6Pase. This may change the activity of other membranebound enzymes that also take part in detoxification. Changes in the direction of enzyme activity may vary, because these enzymes are localized in different membrane domains (Rai et al., 2015).

During liver regeneration, the heterogeneity of cell population increases. This is associated with an increase in the number of Kupffer, star, and oval cells (Russo et al., 2006). In case of liver pathology, oval cells, which are localized in the canals of Hering, are the source of regeneration of hepatocytes. Oval cells are referred to as intrahepatic stem/progenitor cells and can differentiate into hepatocytes and cholangiocytes (Fausto and Campbell, 2003). Furthermore, in the regenerating liver, the heterogeneity of hepatocytes is increased owing to a changing proportion of proliferating cells and emergence of apoptotic and necrotic cells (Cozzolino et al., 2016). The lipid reorganization of cellular membranes may lead to the phenomenon of hepatocyte fusion (Willenbring et al., 2004).

The fluorescent intensity due to formation of lipid peroxidation products in microsomes of the intact and regenerating liver and the decrease of membrane-bound G6Pase activity was assessed. The ratio between the rate of decrease in G6Pase activity and the amount of MDA of the intact and regenerating liver were different. This indicates that during liver regeneration, not only do the quantity and quality of lipid elements increase, but also a cooperative reorganization of ER occurs. This is supported by the presence of differently sized membrane vesicles that were separated in sucrose gradient, which varied between the intact and regenerating liver.

Investigation of the behavior of the ER isolated from livers with different conditions (such as hepatitis, fibrosis, and cirrhosis) can be a promising way to evaluate reversible and irreversible pathological conditions. Additionally, the findings of this study may contribute to the application of isolated microsomes in the evaluation of xenobiotic metabolism. However, in this case, further investigations of the associations of structural and functional characteristics of ER in vivo with behavioral characteristics of microsomes in vitro are necessary.

\section{Compliance with ethics guidelines}

Anatoly Bozhkov, Natalia Menzyanova, Vadim Davydov, Natalia Kurguzova, Vadim Sidorov, and Anastasia Vasilieva declare that they have no conflict of interest.

\section{References}

Alegre M, Ciudad C J, Fillat C, Guinovart J J (1988). Determination of glucose-6-phosphatase activity using the glucose dehydrogenasecoupled reaction. Anal Biochem, 173(1): 185-189

Back S H, Kaufman R J (2012). Endoplasmic reticulum stress and type 2 diabetes. Annu Rev Biochem, 81(1): 767-793

Bozhkov A I, Dlubovskaya V L (1995). Lipid accumulation in the cytosol of liver cells after local hyperthermia and partial hepatectomy. Biochemistry, 60(11): 1816-1824 (in Russian)

Bozhkov A I, Menzianova N C (2009). Calorie restricted diet induces alternative pathways of lipid metabolism for support of proliferative processes in regenerating liver. Adv Gerontol, 22(3): 440-447

Braakman I, Hebert D N (2013). Protein folding in the endoplasmic reticulum. Cold Spring Harb Perspect Biol, 5(5): a013201

Cao S S, Kaufman R J (2014). Endoplasmic reticulum stress and oxidative stress in cell fate decision and human disease. Antioxid Redox Signal, 21(3): 396-413

Cozzolino A M, Noce V, Battistelli C, Marchetti A, Grassi G, Cicchini C, Tripodi M, Amicone L (2016) Modulating the Substrate Stiffness to Manipulate Differentiation of Resident Liver Stem Cells and to Improve the Differentiation State of Hepatocytes. Stem Cells Int, 2016: 5481493

Dai L J, Li H Y, Guan L X, Ritchie G, Zhou J X (2009). The therapeutic potential of bone marrow-derived mesenchymal stem cells on hepatic cirrhosis. Stem Cell Res (Amst), 2(1): 16-25

Fagone P, Jackowski S (2009). Membrane phospholipid synthesis and endoplasmic reticulum function. J Lipid Res, 50(Suppl): S311-S316

Fausto N, Campbell J S (2003). The role of hepatocytes and oval cells in liver regeneration and repopulation. Mech Dev, 120(1): 117-130

Fausto N, Riehle K J (2005). Mechanisms of liver regeneration and their clinical implications. J Hepatobiliary Pancreat Surg, 12(3): 181-189

Fu S, Watkins S M, Hotamisligil G S (2012). The role of endoplasmic reticulum in hepatic lipid homeostasis and stress signaling. Cell Metab, 15(5): 623-634

Hebert D N, Garman S C, Molinari M (2005). The glycan code of the endoplasmic reticulum: asparagine-linked carbohydrates as protein maturation and quality-control tags. Trends Cell Biol, 15(7): 364370

Higgins G M, Anderson R M (1931). Experimental pathology of the liver. I. Restoration of the liver of the white rat following partial surgical removal. Arch Pathol (Chic), 12: 186-202

Jork H, Funk W, Fischer W, Wimmer H (1994): Thin-Layer Chromatography: Reagents and Detection Methods, Volume 1b, $\mathrm{VCH}$, Weinheim

Kamath S A, Narayan K A (1972). Interaction of $\mathrm{Ca}^{2+}$ with endoplasmic reticulum of rat liver: a standardized procedure for the isolation of rat liver microsomes. Anal Biochem, 48(1): 53-61

Keyomarsi K, Sandoval L, Band V, Pardee A B (1991). Synchronization of Tumor and Normal Cells from G1, to Multiple Cell Cycles by 
Lovastatin Cancer Res, 51: 3602-3609

Krishnan K S, Balaram P (1975). Perturbation of lipid structures by fluorescent probes. FEBS Lett, 60(2): 419-422

Lavoie C, Paiement J (2008). Topology of molecular machines of the endoplasmic reticulum: a compilation of proteomics and cytological data. Histochem Cell Biol, 129(2): 117-128

Lowry O H, Rosebrough N J, Farr A L, Randall R J (1951). Protein measurement with the Folin phenol reagent. J Biol Chem, 193(1): 265-275

Ohkawa H, Ohishi N, Yagi K (1979). Assay for lipid peroxides in animal tissues by thiobarbituric acid reaction. Anal Biochem, 95(2): 351358

Rai A K, Bhaskar N, Baskaran V (2015). Effect of feeding lipids recovered from fish processing waste by lactic acid fermentation and enzymatic hydrolysis on antioxidant and membrane bound enzymes in rats. J Food Sci Technol, 52(6): 3701-3710

Russo F P, Alison M R, Bigger B W, Amofah E, Florou A, Amin F, BouGharios G, Jeffery R, Iredale J P, Forbes S J (2006). The bone marrow functionally contributes to liver fibrosis. Gastroenterology, 130(6): 1807-1821

Schneiter R, Toulmay A (2007). The role of lipids in the biogenesis of integral membrane proteins. Appl Microbiol Biotechnol, 73(6): 1224-1232

Schönthal A H (2012). Endoplasmic reticulum stress: its role in disease and novel prospects for therapy. Scientifica (Cairo), 2012: 857516

Schwarz D S, Blower M D (2008). Topology of molecular machines of the endoplasmic reticulum: a compilation of proteomics and cytological data. Histochem Cell Biol, 129(2): 117-128

Sukach A N, Bozhkov A I, Menzyanova N G, Sklyar A I, Belous A M (1997). Isolation of two fractions of hepatocytes and characterization of lipid composition. Ukr. biochim. zhurnal, (in Russian) 69(4): 5360

Thiam A R, Farese R V Jr, Walther T C (2013). The biophysics and cell biology of lipid droplets. Nat Rev Mol Cell Biol, 14(12): 775-786

Vitale A, Ceriotti A, Denecke J (1993). The Role of the Endoplasmic Reticulum in Protein Synthesis, Modification and Intracellular Transport. J Exp Bot, 44(9): 1417-1444

Wagner M, Moore D D (2011). Endoplasmic reticulum stress and glucose homeostasis. Curr Opin Clin Nutr Metab Care, 14(4): 367373

Walter P, Ron D (2011). The unfolded protein response: from stress pathway to homeostatic regulation. Science, 334(6059): 10811086

Willenbring H, Bailey A S, Foster M, Akkari Y, Dorrell C, Olson S, Finegold M, Fleming W H, Grompe M (2004). Myelomonocytic cells are sufficient for therapeutic cell fusion in liver. Nat Med, 10(7): 744-748

Wynn T A (2008). Cellular and molecular mechanisms of fibrosis. J Pathol, 214(2): 199-210

Zimmerman D W (1997). A Note on Interpretation of the PairedSamples t Test. Journal of Educational and Behavioral Statistics, 22 (3): 349-360 